\title{
Journal of Materials Science
}

December 2010, Volume 45, Number 23, Pages

$6395-6400$

http://dx.doi.org/10.1007/s10853-010-4721-z

(C) Springer Science+Business Media, LLC 2010

The original publication is available at http://www.springerlink.com

\section{Tensile fatigue behaviour of PBO fibres}

\author{
P. Davies ${ }^{1,{ }^{*}}$, A. R. Bunsell ${ }^{2}$ and E. Chailleux ${ }^{3}$ \\ ${ }^{1}$ IFREMER, Centre de Brest, Materials \& Structures Laboratory, Plouzané, 29280, France \\ ${ }^{2}$ Centre des Matériaux, Ecole de Mines de Paris, Evry, 91003, France \\ ${ }^{3}$ Laboratoire Centrale des Ponts et Chaussées, Bouguenais, 44341, France \\ *: Corresponding author : P. Davies, email address : peter.davies@ifremer.fr
}

\begin{abstract}
:
Poly( $p$-phenylene benzobisoxazole) (PBO) fibres are finding increasing applications on account of their exceptional stiffness and strength. This article presents results from tests on single PBO filaments, to characterize their intrinsic behaviour under quasi-static and cyclic tensile loading. Scanning electron microscopy is used to show the fibrillation mechanism leading to failure. Results are compared to data for polyester, aramid and high modulus polyethylene fibres. PBO fibres show shorter fatigue lifetimes than the other fibres when maximum stress is expressed as a percentage of quasistatic break load, but the absolute stress values applied are much higher for an equivalent lifetime.
\end{abstract}




\section{- Introduction}

Polybenzazole polymers were developed by the US Air Force in the 1980's [1], and PBO poly(p-phenylene benzobisoxazole) fibres were first presented by Krause et al [2]. Several authors have discussed their morphology, and Kitagawa et al. proposed a model for the structure of the currently commercialized PBO fibers [3]. The mechanical properties of these fibres are exceptional, Young et al. [4] and Orndoff [5] have presented quasi-static mechanical properties, and structure-property relationships were described by Kitagawa et al. [6]. The fibre suppliers also provide mechanical property data under tensile creep loading [7]. There are many high performance polymer fibres commercially available, including a range of aramids and high modulus polyethylenes (HMPE), Table 1, but manufacturers' data indicate that PBO shows some of the highest properties. Two grades are available, under the trade name Zylon ${ }^{T M}[7]$.

Table 1. Comparison of typical commercial fibre property ranges (suppliers' data).

Two weaknesses of the PBO fibre have been detected. First, it is very sensitive to light [8], so PBO fibre ropes are always protected by outer covers. Second, moisture can also affect properties $[9,10]$. Although these fibres have been commercially available for over ten years, and are now widely used in high performance ropes, particularly for racing yacht rigging, there are very few data available on their fatigue properties. This paper provides results from quasi-static and cyclic tensile tests on high modulus grade PBO fibres in order to evaluate their fatigue behaviour and compare it to that of other commercially available fibres.

\section{Materials and experimental methods}

The high modulus grade of PBO was used in this study. A new bobbin of zero twist fibres was supplied by Toyobo (Japan) for tests. Both quasi-static and cyclic fibre tests were performed on single fibres on the test machine developed by Bunsell \& Hearle [11], Figure 1.

\section{Figure 1. Fibre test machine}

Samples were bonded between two cardboard frames using a neoprene adhesive, fibre diameter was measured with a laser interferometer on each fibre, the sample was then placed in the machine grips and the cardboard window was cut. Thirty samples were tested for each 
condition, on 50mm long specimens. Fibres appear smooth, Figure 2a, and are approximately circular, Figure 2b. A circular cross-section was assumed for stress calculations and strain values were corrected to account for machine rigidity.

Figure 2. Fibres before test, a) SEM photo of fibre, b) Polished sections of fibres potted in resin.

Fracture morphologies of the fibres were observed with a Gemini 982 Zeiss scanning electron microscope (SEM) fitted with a field effect gun which allows studies to be performed at low accelerating voltages. For this study a voltage of $2 \mathrm{kV}$ was used. The fibres were however coated with gold-palladium, to avoid any possible problem of charging. The complementary ends of broken fibres were examined.

\section{Results}

\section{Quasi-static tests}

Tensile test results are summarized in Table 2, examples of stress-strain plots and a histogram showing all the break stresses are shown in Figure 3.

Table 2. Suppliers' data and measured properties

Figure 3. PBO fibre quasi-static tensile tests.

a) Examples of stress-strain plots

b) Histogram showing break loads from 30 tests.

Modulus values are very close to expected values. Mean measured tensile strengths are lower than the datasheet value, but scatter is quite high and, as seen in Figure 3 some values close to $6000 \mathrm{MPa}$ were measured. The datasheet values were determined on yarns with optimum twist for strength, which increases strength by about $10 \%$ compared to untwisted yarn but reduces modulus by a similar amount [7]. Tensile failure involves splitting and fibrillation, Figure 4a, a mechanism seen in many highly oriented fibres [12]. After failure a compression stress wave results in compression bands, Figure $4 \mathrm{~b}$. 
Figure 4. PBO tensile fracture surfaces, quasi-static test, a) longitudinal splitting, b) compression bands.

\section{Cyclic tests}

PBO fibres were cycled at $50 \mathrm{~Hz}$ between 0 and $70 \%$ of the mean measured tensile breaking load (5030 MPa). Results were obtained from 30 valid tests (failure away from the grips). A smaller number of tests were performed at a second stress level, $60 \%$ of static break strength. Figure 5 shows a plot of failure probability versus cycles to failure for PBO at the two maximum stress levels.

Figure 5. Failure probability versus cycles to failure, $P B O$

Examination of the fracture surfaces of fibres in the SEM once again revealed extensive fibrillation. Fibres which had survived for longer times tend to peel from deeper within the fibre than those which failed more quickly, Figure 6, and the fibrillation length appears to increase with cycling time. This suggests that crack propagation contributes to the failure process.

Figure 6. PBO fracture surfaces, cyclic tests 0-70\%.

\section{Discussion}

It is interesting to examine these results with respect to those for other fibres. Data have been measured using the same test set-up in previous studies on polyester [13], aramid (Kevlar29) [14] and HMPE (Dyneema SK75) [15] fibres. Figure 7 shows a comparison with these fibres at the same cycling range of $0-70 \%$ break load. Polyester fibres are generally considered to be fatigue resistant, and in large ropes their fatigue performance has been shown to be better than that of steel cables used for mooring offshore platforms [16]. This comparison shows that the fatigue lifetimes of PBO are shorter than those of the other fibres when compared on this basis. Recent studies by Raman spectroscopy have improved our understanding of the mechanisms involved in fatigue behaviour of polymer fibres [17]. Thermoplastic fibres such as PA 66 and PET fail by similar fatigue processes, involving distinct stages of crack growth leading to distinctive fracture morphologies. It appears that the ordering of the amorphous 
polymer chains in such fibres provides an essential contribution to fatigue crack resistance, and the highly crystalline PBO fibres do not benefit from this. In addition the particular microstructure of $\mathrm{PBO}$ fibres, with very little space between chains to accommodate transverse compression, make them quite sensitive to kinking and compression failure [18].

\section{Figure 7. Comparison between PBO and other fibres, probability of failure versus cycles to} failure, 0-70\% cyclic load.

An alternative presentation of the results can be made in terms of the absolute value of maximum stress. Figure 8 and Table 3 show this comparison. Here it is apparent that for the same lifetime the PBO fibres can support much higher maximum stresses than any of the other fibres.

Figure 8. Comparison between PBO and other fibres, maximum applied stress versus median value of cycles to failure.

Table 3. Test details and median cycles to failure

Examples of the cyclic failure modes of the polyester and HMPE fibres in this load range are shown in Figure 9. An aramid fracture from a quasi-static test is also shown, for this fibre it was not possible to distinguish between static and cyclic test fracture surfaces [14]. The polyester fibre fatigue mechanism has been described in detail recently [19], fatigue fracture surfaces are quite different to those found after tensile or creep tests which do not show the long peeled tongue. The high performance fibres HMPE and aramid show similar fractures to the PBO in static and cyclic tests, with extensive fibrillation.

Figure 9. Failure modes, a) polyester, b) HMPE, c) aramid

At high loads there is a tendency for creep failure to replace the fatigue mechanism. This can be examined by comparing the lifetimes under constant load (creep) and cyclic load (fatigue) conditions. Polyester, HMPE and aramid fibres all show significantly shorter lifetimes under fatigue loading, indicating that a distinct failure mechanism is deteriorating the fibres under cyclic loads $[14,15,19]$, even though this is not detectable on broken sample fracture surfaces. 
PBO fibres show very little creep even at high loads [7] so fatigue is likely to be the main concern in design.

Only one type of loading condition, involving complete unloading during each cycle, has been described here, as this is usually the most severe case (without deliberately adding compression). Maintaining a non-zero minimum load can prevent the fatigue mechanism developing, and this has been described elsewhere [14,19-21].

\section{Conclusions}

Tests on single PBO filaments have shown the exceptional static and cyclic properties of these fibres. A single PBO fibre can support much higher cyclic stresses than other fibres. Failure occurs by fibrillation under both static and cyclic loads, in a similar way to that observed in other high performance fibres.

These results show the intrinsic material fatigue performance of PBO fibres. In applications such as ropes, assemblies of large numbers of fibres are used, and the fatigue behaviour may be dominated by construction effects (crossover points in braids, cover/core interactions, terminations). The remarkable potential of the fibres may not then be fully realized, and work is underway to explore the translation of fibre performance to ropes.

\section{Acknowledgements}

The authors acknowledge the contributions of Eric Gacoin, Christope Teissedre, and Yves Favry to the test data presented here.

\section{References}

[1] Ulrich DR, Multifunctional macromolecular ultrastructures, Polymer, 28, (1987), 553-542

[2] Krause SJ, Haddock TB, Vezie DL, Lenhert PG, Hwang WF, Price GE, Helminiak TE, O'Brien JF, Adams WW, Morphology and properties of rigid-rod poly(p-phenylene benzobisoxazole) (PBO) and stiff-chain poly(2,5(6)-benzoxazole) (ABPBO) fibres, Polymer, $29,8,(1988), 1354-1364$

[3] Kitagawa $\mathrm{T}$, Murase $\mathrm{H}$, Yabuki $\mathrm{K}$, Morphological study on poly-pphenylenebenzobisoxazole (PBO) fibre, J. Polymer Sci, Part B, 36, (1998) 39-48.

[4] Young RJ, Day RJ, Zakikhani M, The structure and deformation behaviour of poly(pphenylene benzobisoxazole) fibres , Journal of Materials Science, 25, 1 (1990), 127-136.

[5] Orndoff E, Development and evaluation of polybenzoxazole fibrous structures, NASA Tech Memo 104814, September (1995). 
[6] Kitagawa T, Yabuki K, Young RJ, An investigation into the relationship between processing, structure and properties for high-modulus PBO fibres. Part 1. Raman band shifts and broadening in tension and compression, Polymer, Volume 42, Issue 5, (2001), 2101-2112 [7] Toyoba Co., Technical information datasheet, Super high performance fiber Zylon, (1998).

[8] Said M.A., Dingwall B, Gupta A., Seyam A.M., Mock G, Theyson T, Investigation of ultra violet (UV) resistance for high strength fibers, Advances in Space Research, 37, 11, (2006), 2052-2058

[9] Cervenka A.J., Young R.J. Kueseng K, Micromechanical phenomena during hygrothermal ageing of model composites investigated by Raman spectroscopy. Part II: comparison of the behaviour of PBO and M5 fibres compared with Twaron, Composites Part A, 36, 7, (2005), $1020-1026$

[10] Chin J, Forster A, Clerici C, Sung L, Oudina M, Rice K, Temperature and humidity aging of poly(phenylene-2-6-benzobisoxazole fibers: chemical and physical characterization, Polymer Degradation \& Stability, 92, (2007), 1234-1246.

[11] Bunsell AR, Hearle JWS, Hunter RD, An apparatus for fatigue-testing of fibres, Journal of Physics E - Scientific Instruments, Vol. 4, (1971) 868-872.

[12] Hearle JWS, Lomas B, Cooke WD, Atlas of fibre fracture and damage to textiles, $2^{\text {nd }}$ Edition, Woodhead Publishing, 1998.

[13] Lechat C, Bunsell AR, Davies P, Piant A, Mechanical behaviour of polyethylene terephthalate \& polyethylene naphthalate fibres under cyclic loading, J Materials Science 41 (2006) 1745-1756

[14] Lafitte MH, Bunsell AR, The fatigue behaviour of Kevlar-29 fibres, Journal of Materials Science, 17, 8, (1982) 1300-1308.

[15] Unpublished data, Ecole des Mines de Paris, 2002.

[16] Banfield, S.J., Casey NF, Nataraja R, Durability of. Polyester Deepwater Mooring Rope, OTC 17510, Offshore Technology Conference proceedings, (2005).

[17] Herrera Ramirez JM, Colomban P, Bunsell A, Micro-Raman study of the fatigue fracture and tensile behaviour of polyamide (PA 66) fibres, J. Raman Spectroscopy 35, (2004) 10631072.

[18] Colomban P, Aidi-Mounsi A, Limage M-H, Micro-Raman and IR study of the compressive behaviour of poly(paraphenylene benzobisoxazole) (PBO) fibres in a diamondanvil cell, J. Raman Spectroscopy 38 (2007) 100 
[19] Le Clerc C, Bunsell AR, Piant A, Monasse B, Role of skin/core structure and inclusions in the fatigue crack initiation and propagation in organic fibres, Journal of Materials Science, (2006),41, 20

[20] Tanaka K, Minoshima K, Oya T, Komai K, Influences of stress waveform and wet environment on fatigue fracture behavior of aramid single fiber, Comp. Sci \& Tech., 64, (2004), 1531-1537.

[21] Bunsell AR, Tensile fatigue of thermoplastic fibres, in 'Handbook of tensile properties of textile and technical fibres', Ed. A.R.Bunsell, Woodhead Publishing Ltd., Oxford, (2009), 332-353. 


\begin{tabular}{|l|c|c|c|}
\hline Fibre & Density & Stiffness, GPa & Strength, MPa \\
\hline PBO (Zylon HM) & 1.56 & 280 & 5800 \\
\hline Polyester (High Tenacity) & 1.38 & 15 & 1300 \\
\hline Aramid (Kevlar 29) & 1.44 & 70 & 2920 \\
\hline HMPE (Dyneema SK75) & 0.97 & 110 & 3500 \\
\hline
\end{tabular}

Table 1. Comparison of typical commercial fibre property ranges (suppliers data).

\begin{tabular}{|l|c|c|c|}
\hline Sample & Stiffness, GPa & Strength, MPa & Diameter, $\mu \mathbf{m}$ \\
\hline Supplier data [7] & 280 & 5800 & - \\
\hline Measured values & $290 \pm 15$ & $5030 \pm 750$ & $11.2 \pm 0.6$ \\
\hline
\end{tabular}

Table 2. Suppliers' data and measured properties, PBO HM.

\begin{tabular}{|l|l|l|c|c|}
\hline Material & Break stress & $\begin{array}{l}\text { Maximum } \\
\text { applied stress } \\
\text { level }\end{array}$ & $\begin{array}{c}\text { Median } \\
\text { Cycles to fail }\end{array}$ & $\begin{array}{l}\text { Number of } \\
\text { valid tests }\end{array}$ \\
\hline PBO HM & 5030 & $60 \%$ & 514800 & 7 \\
& & $70 \%$ & 21060 & 30 \\
\hline PET & 1260 & $70 \%$ & 206550 & 19 \\
& & $75 \%$ & 149400 & 19 \\
& & $80 \%$ & 19800 & 19 \\
\hline HMPE SK75 & 3700 & $60 \%$ & 118800 & 23 \\
& & $65 \%$ & 117000 & 12 \\
& & $70 \%$ & 59400 & 27 \\
& & $75 \%$ & 13500 & 28 \\
\hline Aramid K29 & 2600 & $56 \%$ & 730000 & 25 \\
[14] & & $70 \%$ & 260000 & 21 \\
\hline
\end{tabular}

Table 3. Test details and median cycles to failure 


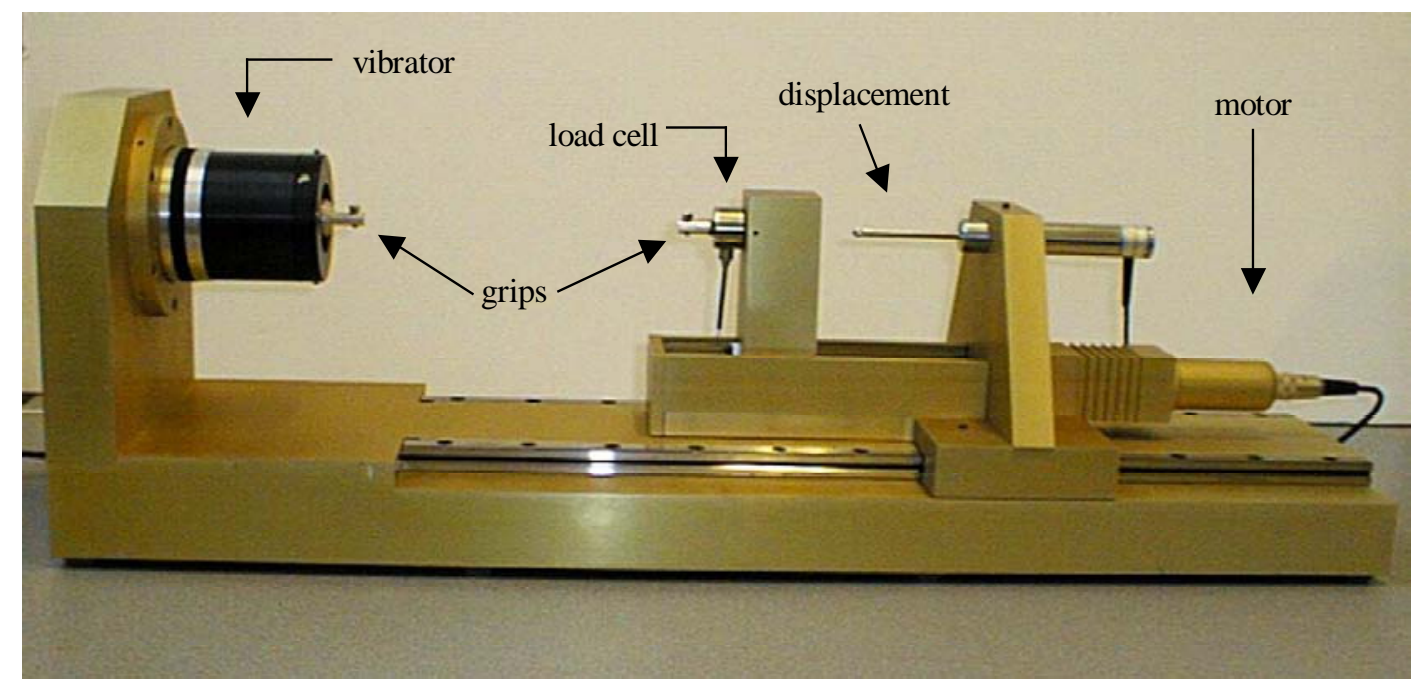

Figure 1. Fibre test machine

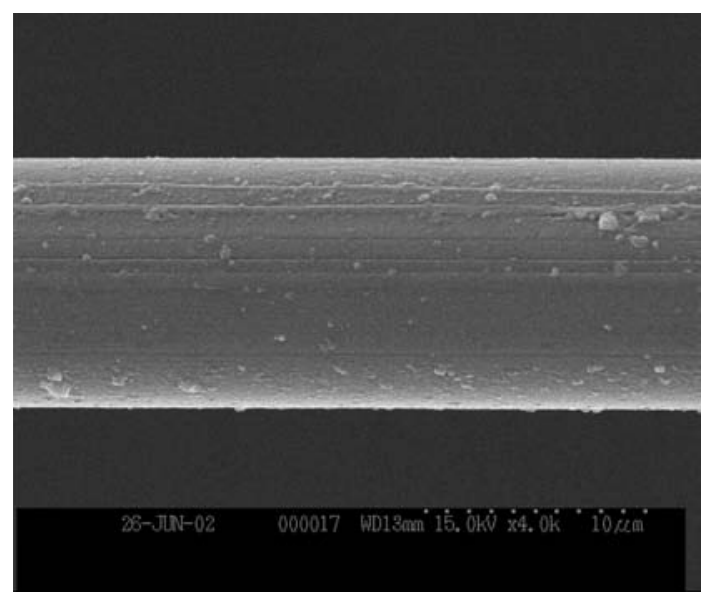

a

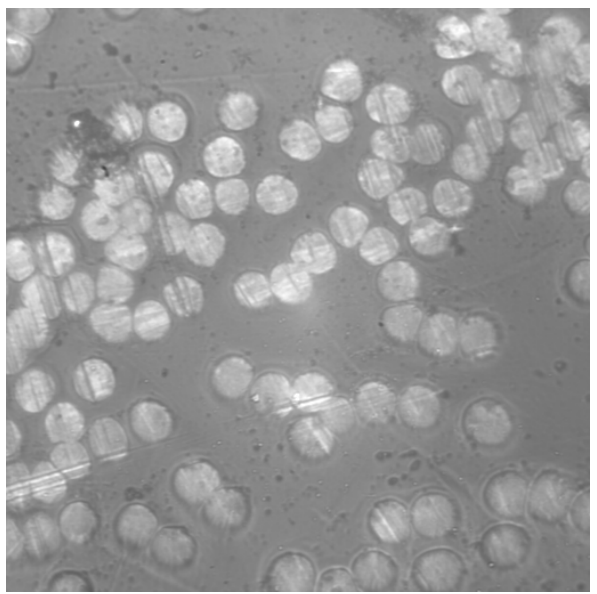

b

Figure 2. PBO fibres before test, a) SEM photo of fibre, b) Polished sections of fibres potted in resin. 


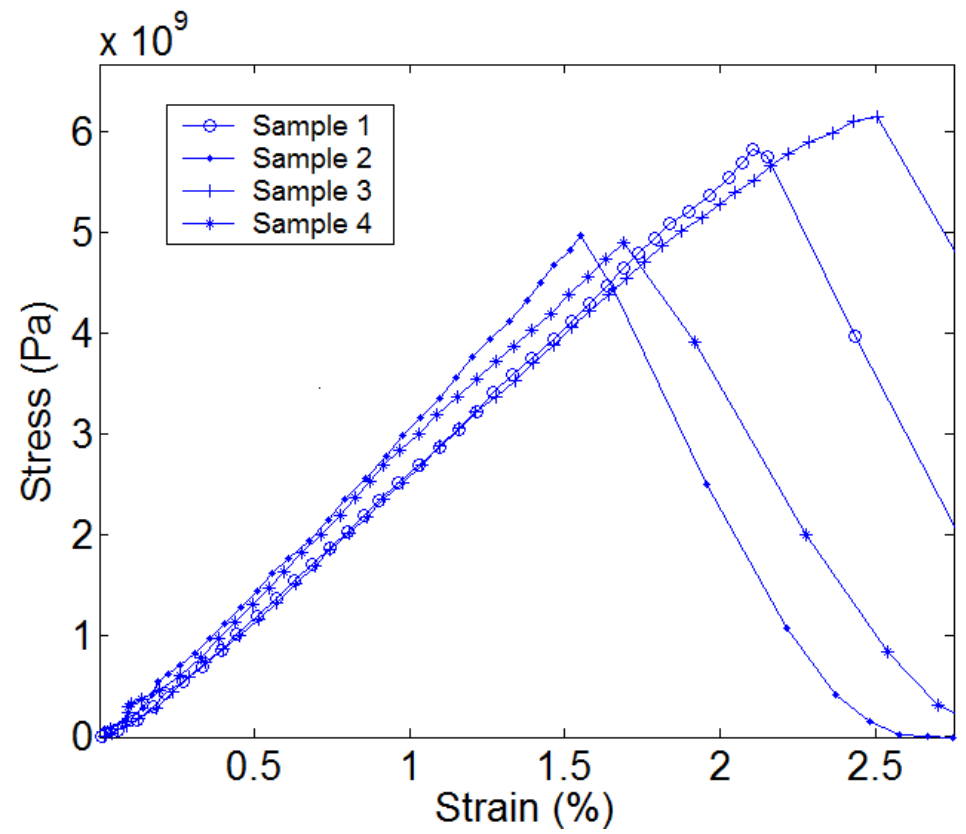

(a)

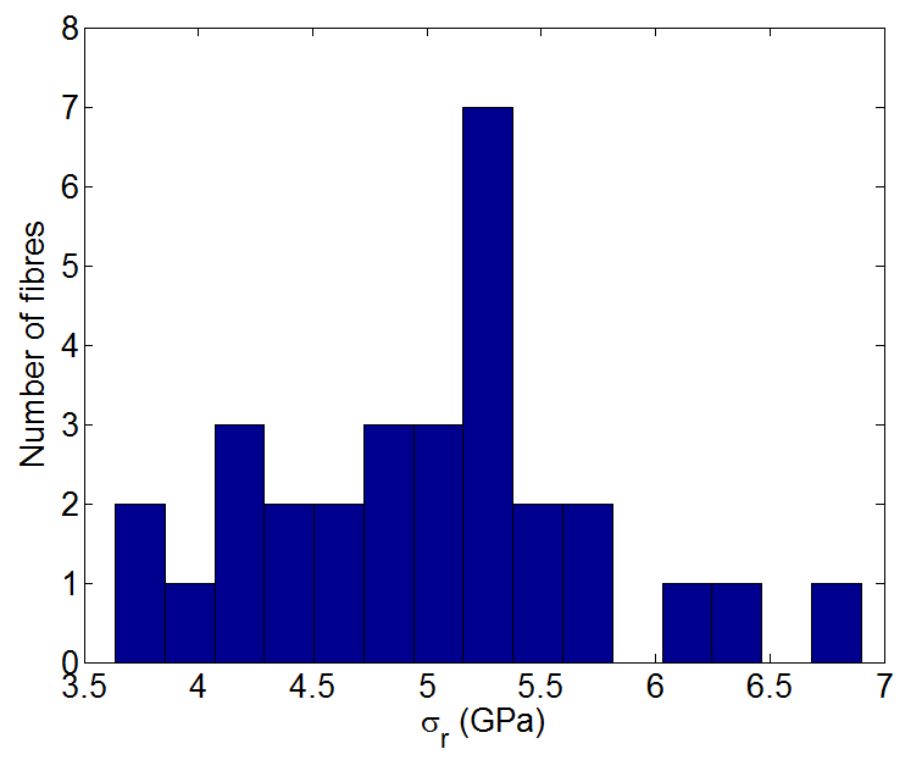

(b)

Figure 3. PBO fibre quasi-static tensile tests.

a) Examples of stress-strain plots

b) Histogram showing break loads from 30 tests. 

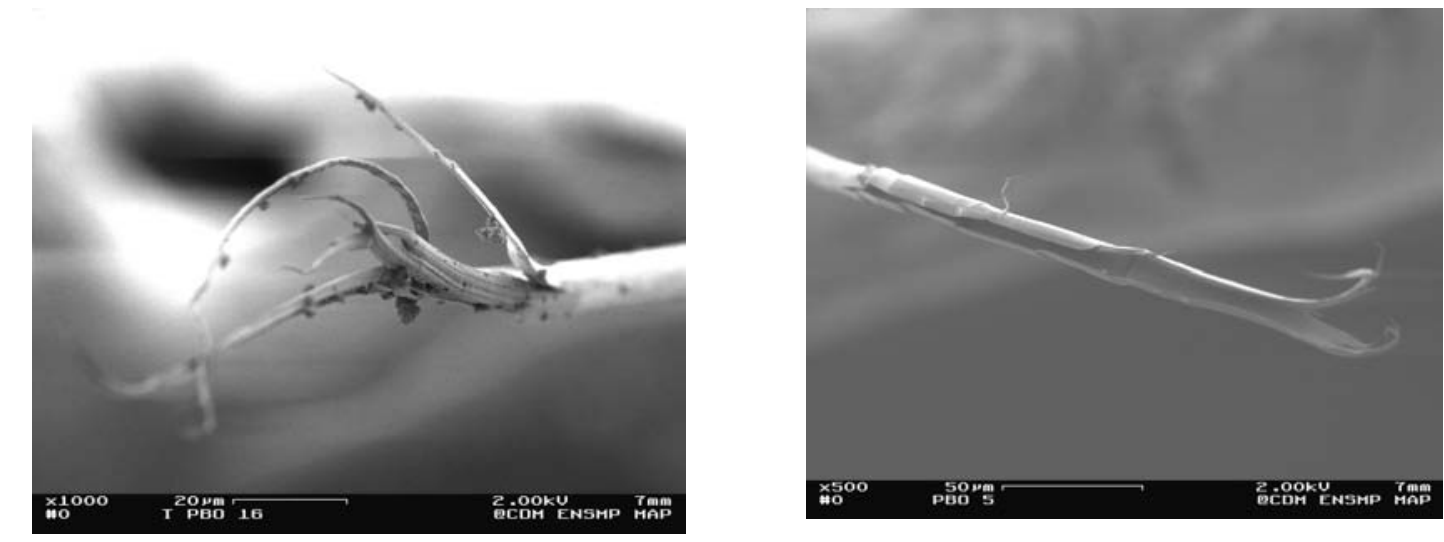

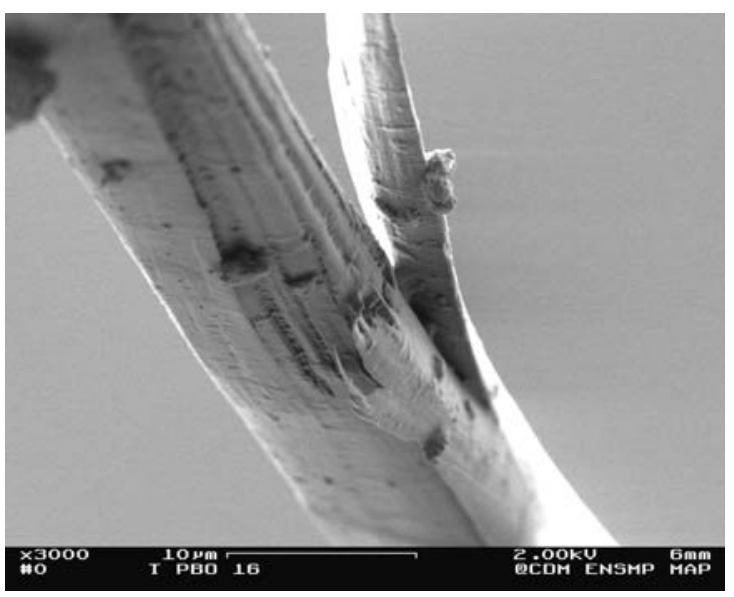

(a)

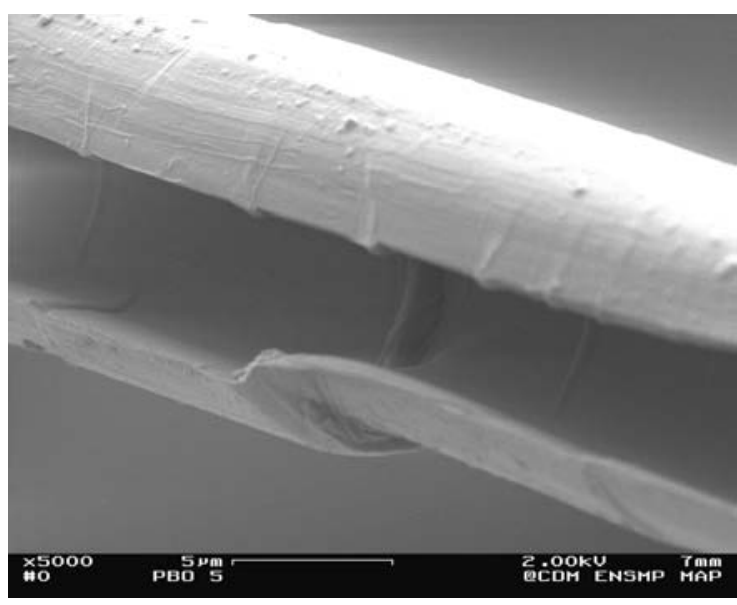

(b)

Figure 4. PBO tensile fracture surfaces, quasi-static test, a) longitudinal splitting, $b$ ) compression bands.

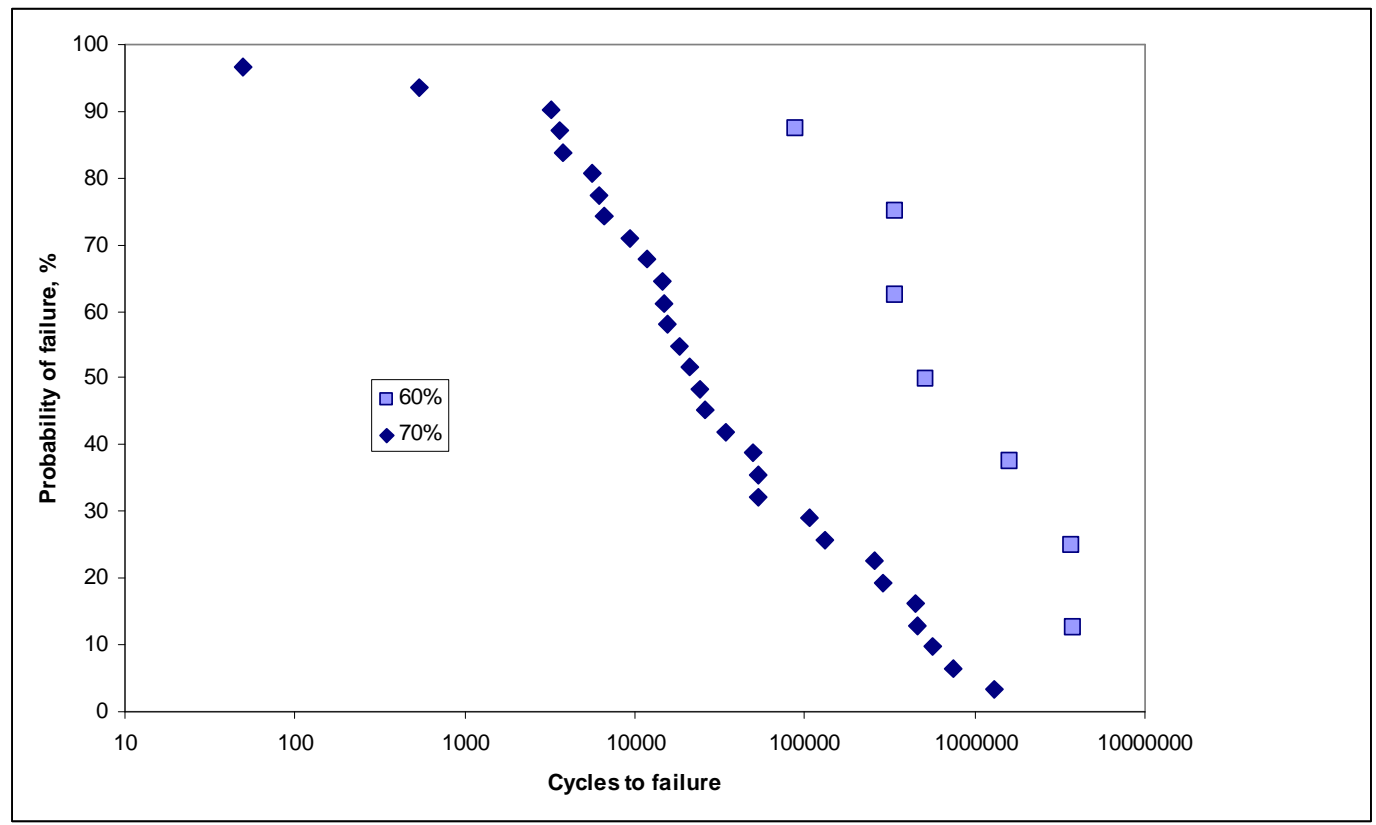

Figure 5. Failure probability versus cycles to failure, $P B O$ with $0-70 \%$ and $0-60 \%$ cycling. 


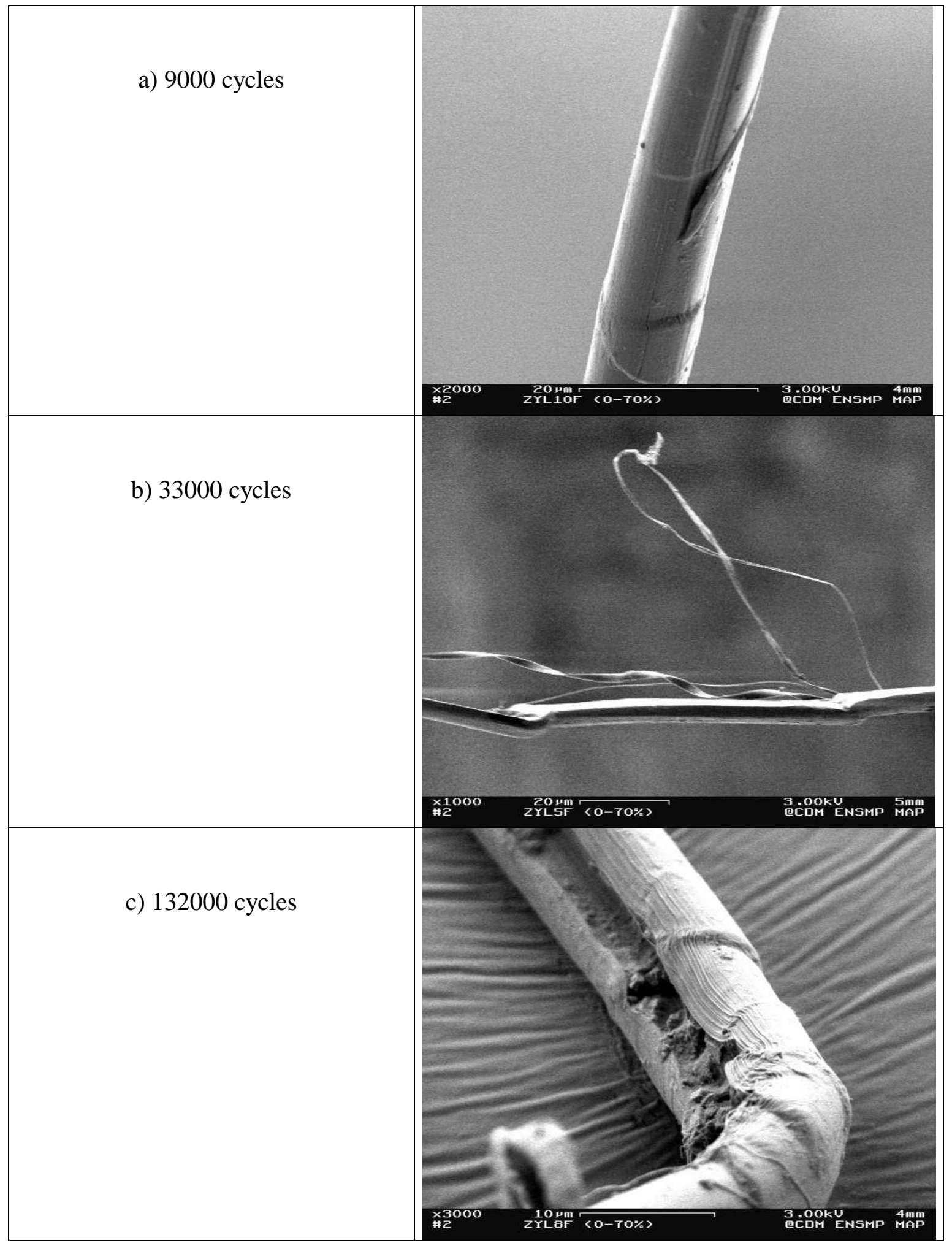

Figure 6. PBO fracture surfaces, cyclic tests. 


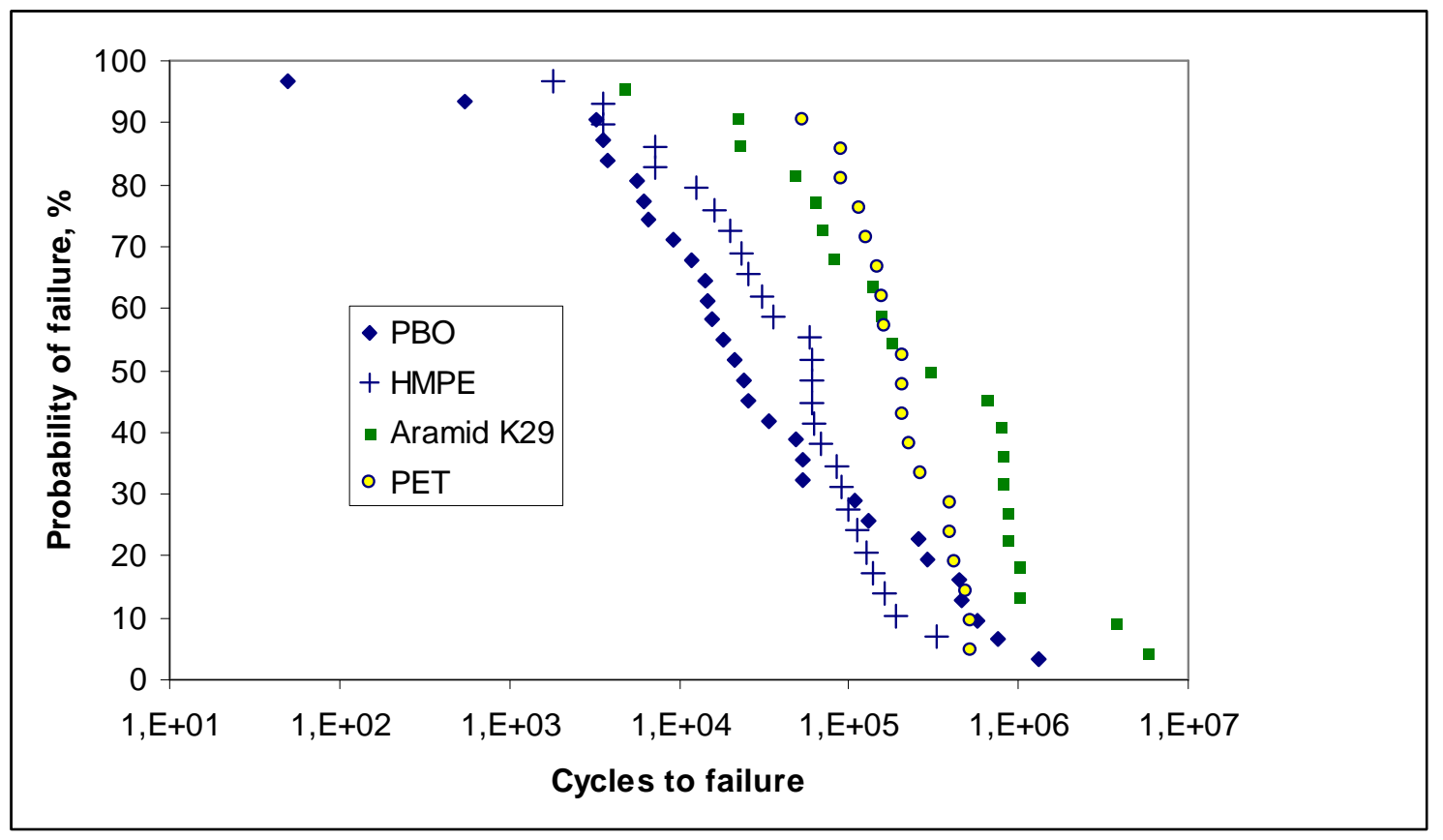

Figure 7. Comparison between fibres, 0-70\% cyclic load.

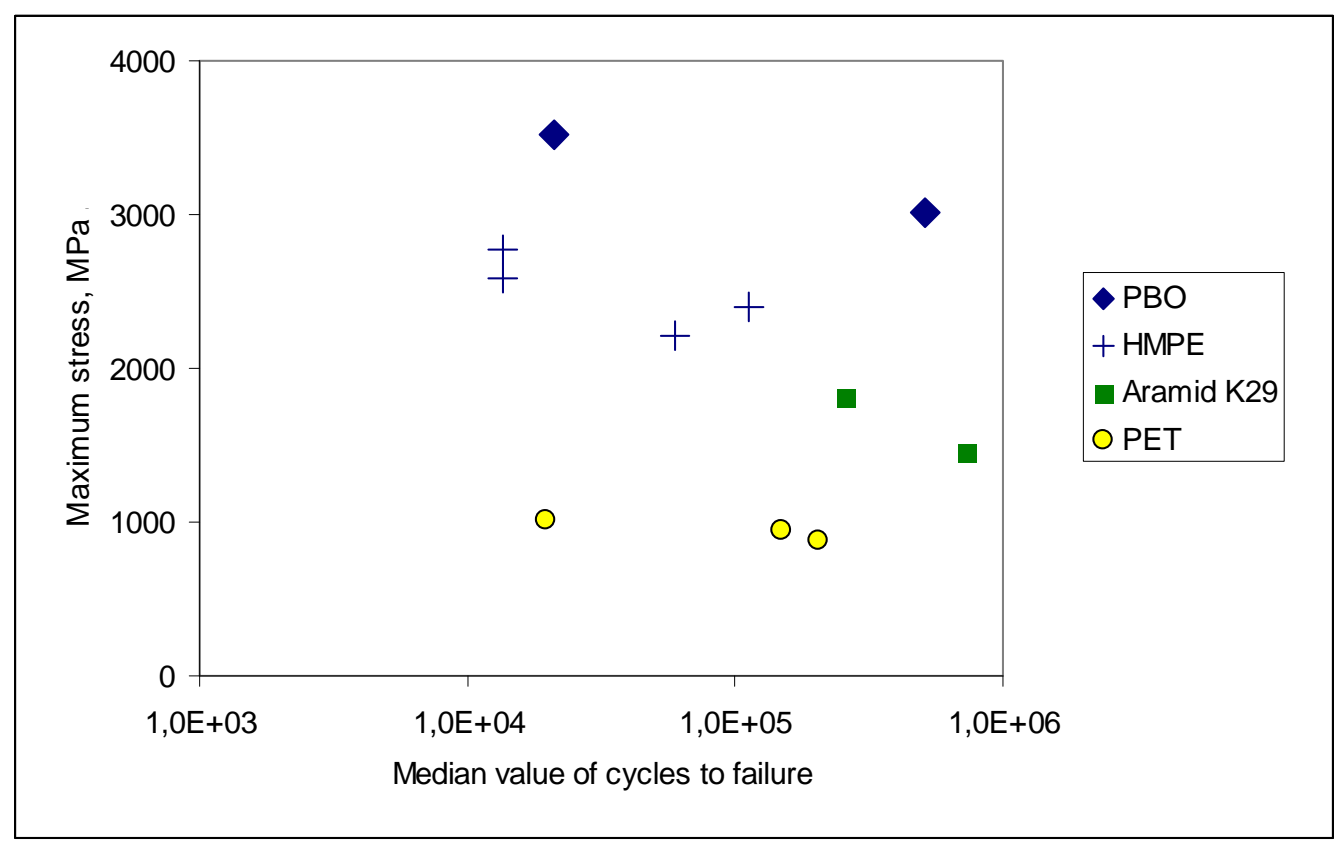

Figure 8. Comparison of PBO cyclic behaviour with polyester, aramid, and HMPE in terms of applied stress. 


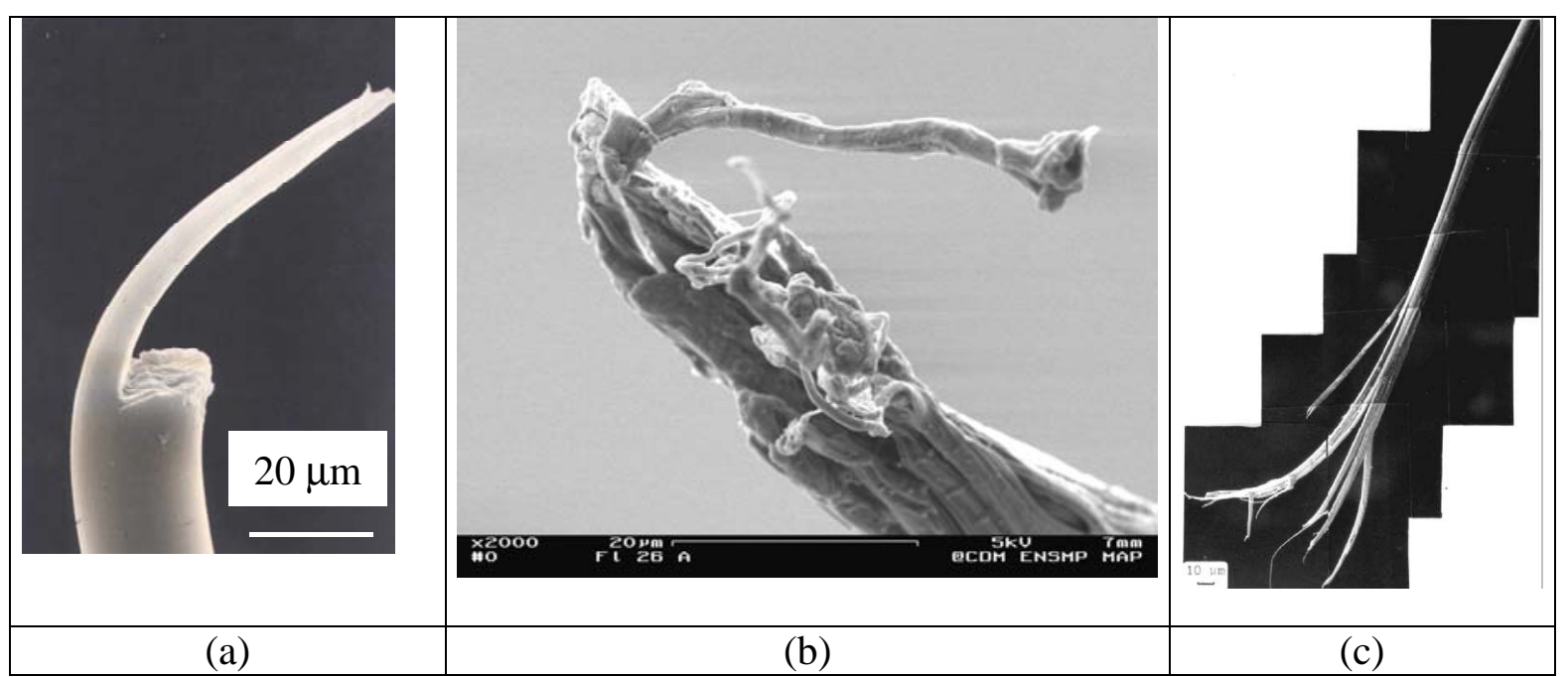

Figure 9. Failure modes, a) polyester (cyclic), b) HMPE (cyclic), c) aramid (static) 